\title{
Understanding consumer liking of beef using hierarchical cluster analysis and external preference mapping
}

Article

Accepted Version

Chong, F. S., O'Sullivan, M. G., Kerry, J. P., Moloney, A. P., Methven, L., Gordon, A. W., Hagan, T. D. J. and Farmer, L. J. (2020) Understanding consumer liking of beef using hierarchical cluster analysis and external preference mapping. Journal of the Science of Food and Agriculture, 100 (1). pp. 245-257. ISSN 1097-0010 doi:

https://doi.org/10.1002/jsfa.10032 Available at https://centaur.reading.ac.uk/86327/

It is advisable to refer to the publisher's version if you intend to cite from the work. See Guidance on citing.

To link to this article DOI: http://dx.doi.org/10.1002/jsfa.10032

Publisher: Wiley

All outputs in CentAUR are protected by Intellectual Property Rights law, including copyright law. Copyright and IPR is retained by the creators or other copyright holders. Terms and conditions for use of this material are defined in the End User Agreement. 


\section{CentAUR}

Central Archive at the University of Reading

Reading's research outputs online 


\title{
Understanding consumer liking of beef using hierarchical cluster analysis and external preference mapping
}

F.S. Chong ${ }^{\mathrm{a}, \mathrm{b}}$, M.G. O’Sullivan ${ }^{\mathrm{b}}$, J.P. Kerry ${ }^{\mathrm{b}}$, A.P. Moloney ${ }^{\mathrm{c}}$, L. Methven ${ }^{\mathrm{d}}$, A.W. Gordon ${ }^{\mathrm{a}}$, T.D.J. Hagan ${ }^{\mathrm{a}}$, L.J. Farmer ${ }^{\mathrm{a}}$

${ }^{a}$ Agri-Food and Biosciences Institute, Food Science Branch and Biometrics and Information Systems, $18 a$ Newforge Lane, Belfast, BT9 5PX, United Kingdom;

${ }^{b}$ School of Food \& Nutritional Sciences, Food Science Building, University College Cork, Cork, Ireland;

${ }^{c}$ Teagasc, Animal \& Grassland Research and Innovation Centre, Grange, Dunsany, Co.Meath, Ireland;

${ }^{d}$ University of Reading, Reading, Berkshire, RG6 6AH, United Kingdom

Corresponding author: +44(0)2890255342, Linda.Farmer@afbini.gov.uk (L.J. Farmer)

\begin{abstract}
Background: This study was conducted to assess if there are differences in consumer liking of beef. Samples were collected from different groups and analyses were conducted, including quantitative descriptive analysis, consumer panels and instrumental analyses. Palatability traits, such as aroma liking (AL), tenderness (TE), juiciness (JU), flavour liking (FL) and overall liking (OL) were rated by consumers.

Results: Warner Bratzler shear force was negatively associated with tender mouthfeel and consumer tenderness score. Cluster analysis identified 4 groups of clusters, which were described as "easilypleased", "bull beef liker", "tender beef liker" and "fastidious" consumers. Cluster group 2 awarded higher score for bulls and located in a separate region on external preference map.

Conclusion: External preference mapping showed the association between consumer liking of beef and sensory attributes.
\end{abstract}

Keywords: preferences, Hierarchical cluster analysis, Preference mapping, Consumer acceptability

Declaration of interest: none.

This article has been accepted for publication and undergone full peer review but has not been through the copyediting, typesetting, pagination and proofreading process which may lead to differences between this version and the Version of Record. Please cite this article as doi: $10.1002 /$ jsfa.10032 


\subsection{Introduction}

One of the challenges faced by the beef industry in determining consumer desires regarding beef eating quality is the fact that consumers may vary in their preferences. While many papers have evaluated the average sensory scores for beef from different sources or sample groups (1-4), it is evident that few individuals may be regarded as "average".

Aroma, tenderness, juiciness and flavour are all important sensory attributes of meat (5). However, different studies have indicated that these traits have differing importance (6-9). It is likely that the relative importance of sensory attributes depends not only on the range of qualities presented but also on the preferences of the consumers sampled. A study on the impact of the three regions of Northern Ireland, Republic of Ireland and Great Britain by Chong, Farmer (10) and Chong, Farmer (11) on consumer liking for grilled beef with a total of 360 consumers provided an opportunity to investigate the differences and similarities between subgroups or "clusters" of this population.

The purposes of this study were (a) to confirm that the beef selected for this experiment from different sexes, hanging methods, breeds and sample position could be differentiated by consumers; (b) to identify cluster groups and characterise how they differ in respect to consumer scores and (c) to determine the relationship between descriptive sensory characteristics and consumer liking using internal and external preference mapping.

\subsection{Literature on the differences in consumer liking of beef}

Customer assessments on intrinsic quality attributes for beef products have a direct relationship with sensory attributes, visual characteristics and structural characteristics $(12,13)$. Sensory profiling attributes are assessed by trained panellists using Quantitative Descriptive Analysis (QDA). This technique provides detailed information about sensory properties of a product and it's a most sophisticated way for product characterisation (14). Preference mapping is very helpful in elucidate the differences in consumer perception (15). In external preference map, consumer sensory scores are regressed onto the principal component analysis (PCA) of beef sensory characteristics (16).

Since consumers are highly variable, hierarchical cluster analysis, a long established method, can be used to differentiate human behaviour and identify consumer preference $(17,18)$. It has been used in multiple food sectors such as genetically modified food (19), organic food (20) and low fat salami (21). This approach has been combined with external preference mapping to identify the sensory attributes that impact cheddar cheese acceptability among cluster groups (22). The technique of 
external preference map was previously used by Oltra, Farmer (23) to demonstrate the relationship between consumer overall liking of beef with sensory attributes by profiling panel, instrumental measurements of texture and flavour. A study conducted by Schmidt, Schilling (24) revealed that consumers could be categorised together based on their liking, descriptive sensory attributes and preference of end-point temperature. Cluster groups identified by Oltra, Farmer (25) and Oltra (26) on consumer liking of grilled lamb longissimus lumborum and grilled beef steaks longissimus dorsi showed that the cluster groups were segregated by their liking of lamb or beef instead of demographic factors (age, gender, income, occupation, number of children or adults in the household). In addition, preference in meat packaging and store format choice of consumers was investigated by using cluster analysis and only a small preference for unpackaged meat products was found in the target market (27).

\subsection{Materials and Methods}

\subsection{Source of beef and sample selection}

Beef striploins $(n=72)$ were sampled from animals from twelve groups (Table 1). These sample groups were selected to provide a wide range of eating qualities for consumers and it was not the primary objective for this study to examine the effects of the sample groups. For this reason the sample numbers are small from each sample group and the production methods were not intended to be directly comparable.

Four of the twelve groups (T1b, T2b, T3b and T4b) were collected from Teagasc Ashtown in Republic of Ireland (ROI). Twelve animals were reared and randomly assigned to 24 months dairy steer and 19 months dairy bull production system. After slaughtering, the two sides of each carcase were hung using straight hung (AT) and tenderstretch (TS) methods, respectively. Carcasses were held at under $4^{\circ} \mathrm{C}$ for 2 days before being divided into fore and hind quarters. The striploins were removed, vacuum packed and delivered to Teagasc Ashtown (ROI) to age for 19 days to achieve 21 days aging period. The striploins were stored at $-20^{\circ} \mathrm{C}$ until further cut up. The frozen striploins were sliced into $25 \mathrm{~mm}$ steaks using a bandsaw and transported to Agri-Food Bioscience Institute (AFBI) in polystyrene box with ice packs (journey time: 5 hours). The sliced steaks were labelled with number 1 to 15 from the anterior to posterior of the striploin. Steaks 1 and 11 were stored as spare steaks. Steak 6 was used for instrumental analysis. All the other steaks were classified into three positions; anterior (steak 2 to 5), middle (steak 7 to 10), posterior (steak 12 to 15). These frozen steaks (except steaks 1 , 6 and 11) were partially thawed for 30 minutes and further cut into smaller samples (ca. $50 \times 50 \mathrm{x}$ 
$25 \mathrm{~mm}$ ) for sensory and consumer panels. The samples were transferred to a commercial freezer immediately after portioning.

Striploins from the remaining groups (T1a, T2a, T3a, T4a, T5a, T5b, T6a and T6b) were identified from commercial throughput and purchased from a local abattoir in Northern Ireland (NI). It is important to note that, for the NI animals, the AT and TS sides were from different animals. Average age for continental bulls (T1a and T2a) and continental steers (T3a and T4a) were 15 months and 24 months, respectively. Older cows (T5a, T5b, T6a and T6b) ranged in age from 35 to 188 months. The chilled striploins were transported to AFBI in polystyrene box (journey time: 30 minutes). The striploins were sliced into $25 \mathrm{~mm}$ steaks using a sharp knife. The steaks were labelled, classified into three positions and further cut into smaller samples similarly to the steaks from UCC. The samples were aged until 21 days postmortem and transferred to a commercial freezer and held at $-20^{\circ} \mathrm{C}$ until further analysis.

\subsection{Instrumental analysis}

The ultimate $\mathrm{pH}$ was measured from each striploin using a calibrated $\mathrm{pH}$ meter (Extech instrument, Waltham, MA) between 96 to 120 hours post-mortem at $7.5^{\circ} \mathrm{C}$. Warner Bratzler shear force (WBSF) measurements were performed on the first slice of the anterior end of every striploin using an Instron 2350-416 (Instron Calibration Laboratory, Norwood, United State) following a standard procedure (28). Steaks were tempered at $2^{\circ} \mathrm{C}$ for 24 hours prior to the experiment. The outer fat of the steaks was trimmed off and the pre-cooked weight was recorded. Steaks were then vacuum-packed and cooked in a waterbath for 50 minutes to achieve an internal temperature of $75^{\circ} \mathrm{C}$. This cooking method was selected because it is a standard method for WBSF analysis $(28,29)$. After cooking, the steaks were immersed into a basin filled with ice water for 30 minutes. Cooked weight was recorded and the steaks were stored at $2^{\circ} \mathrm{C}$ overnight. A minimum of eight sample cores $(13 \mathrm{~mm}$ diameter) were obtained from each steak at a parallel angle to the muscle fibres. The crosshead speed of the Instron device was set as $100 \mathrm{~mm} / \mathrm{min}$ with $550 \mathrm{kgf}$ load cell and V shaped blade. The V shaped blade cut the cores at a perpendicular angle to the muscle fibres. Data was exported from BlueHill 3 (Instron software). Cooking loss was calculated with the equation: Cooking loss $=[$ (pre-cooked weight of steak- cooked weight of the steak)/ pre-cooked weight of steak]*100.

\subsection{Quantitative Descriptive Analysis (QDA)}

Eight panellists (4 males and 4 females) were trained for QDA. Extra samples were used in training sessions for sample familiarisation and generation of attributes. Three training sessions were 
conducted with a system adapted from Labbe, Rytz (4) and each session lasted for 2 hours. Attributes were generated for appearance, texture, aroma, flavour and aftertaste (Table 2).

Steak samples were prepared and presented to panellists according to a Latin square design using Biosystem Fizz Acquisition (Biosystem, Dijon, France). Frozen samples (50 x 50 x 25mm) were tempered at $2{ }^{\circ} \mathrm{C}$ for 24 hours prior to the session. The cooking protocol was adapted from that described for "medium"-cooked beef by Watson, Gee (30) to generate well-done steak as follows. Preliminary trials were conducted using a SILEX grill (S-143, SILEXIA UK. Ltd, Oxon, United Kingdom) to determine the cooking time needed to deliver steak with an internal temperature of $72^{\circ} \mathrm{C}$ - this was found to require 4 minutes. Four samples were cooked in each round. The internal temperature was recorded for each steak and a small sample was collected for microbiological assessment, if required. After a 2 minutes of resting period, samples were cut in half and served to 2 panellists. Samples were presented on a white ceramic plates labelled with 3 random digit codes. The panellists rated the intensities of attributes on a line scale ( $0=$ low intensity; $100=$ high intensity). Water was provided as palate cleanser between samples.

\subsection{Consumer panels}

A total of 360 consumers were recruited from three different locations, Northern Ireland, Republic of Ireland and Great Britain, as described elsewhere (11). All consumers were over 18 and consumed beef regularly. Participants were recruited from charity groups, societies, recruitment website, local forum and poster advertising. Clear instructions including location of the study, arrival information, allocated session time and allergens information were given to participants prior to the panel commenced. Consumers were asked to complete a questionnaire (11) prior to the tasting, which included 12 questions on socio-demographic and consumer behaviour.

Samples from different groups were assigned to 360 consumers using latin square design to reduce the potential of order effect (31). Portioned samples were thawed at $2^{\circ} \mathrm{C}$ for 24 hours prior to the consumer session. Seven samples were tested by every consumer, with the first sample being used as "link sample" that was not statistically analysed. The remaining six samples were one sample from each of the 6 groups (Table 1), with either (a) continental breed or (b) dairy breed. Samples were cooked following the same method as described for sensory profiling, except that ten samples were cooked in each round. The samples were identified by a random code. For each sample, consumers were asked to rate for aroma liking $(A L)$, tenderness $(T E)$, juiciness (JU), flavour liking $(F L)$ and overall liking $(O L)$ on a line scale ( $0=$ low liking/low satisfaction; $100=$ high liking/ high satisfaction). MQ4 score was calculated for each sample using the Australian MSA model (0.3 TE+ 0.1 JU+ 0.3 
FL+ 0.3 OL). Water and cream crackers (Jacobs cream cracker, United Biscuits UK Ltd, Leicestershire, United Kingdom) were provided as palate cleanser.

\subsection{Statistical analysis}

Cluster groups were generated using hierarchical cluster analysis using the complete linkage methods. The similarity matrix used by the clustering algorithm was calculated using Euclidian distance (25). Random Effect Model variance component (REML) analysis was conducted using linear mixed model methodology to analyse the results of instrumental analysis, QDA and consumer panel. Factors of interest were fitted as fixed effects while nuisance factors (test session, consumer number and animal) were fitted a random effects (Ahrens, 1974). Cluster groups were characterised using sociodemographic information, and the association between sociodemographic groups were analysed using chi-squared analysis. In addition, preference mapping was performed on consumer acceptability scores, descriptive panel, instrument analysis and hierarchical cluster analysis to establish the relationship between consumer acceptability, sensory attributes, WBSF and cluster groups (32). All statistical analysis was carried out using GenStat (GenStat 16.2.0.11713, VSN International Ltd, Hemel Hempstead, United Kingdom). Results were considered significantly different if $\mathrm{P}<0.05$.

\section{Results and Discussion}

4.1 Warner Bratzler Shear Force, Cooking Loss and pHu

Cooking loss, pHu and WBSF are commonly used to measure meat quality $(33,34)$ and the results from these instrumental analyses are shown in Table 3. Surprisingly, there was no significant difference $(\mathrm{P}>0.05)$ in $\mathrm{pHu}, \mathrm{WBSF}$ or cook loss between the hanging methods (Table 3$)$. In contrast, Ahnström, Hunt (35) and Lively, Moss (28) reported that pelvic suspension reduced the WBSF of $M$. longissimus dorsi.

Table 3 shows that breed $\mathrm{x}$ sex interaction had significant impacts on $\mathrm{pHu}(\mathrm{P}<0.05)$. The $\mathrm{pHu}$ of meat from continental steers was lower than all meat from bulls and cows while the $\mathrm{pHu}$ of continental bulls was significantly higher than all meat from steers (Figure 1). The pHu of the meat is related to the postmortem glycolytic changes. Insufficient glycogen content or low glycolytic capacity can result in high $\mathrm{pH}$ meat (36). The higher $\mathrm{pH}$ observed in the meat of continental bulls may result from the 
fact that bulls are more sensitive to different stress factors and sexual activity $(37,38)$. These findings agree with the study conducted by Węglarz (39), who reported a higher $\mathrm{pH}$ value of 6.1 for summer season young bulls ( 24 months old) and bulls (above 24 months) suggested to be because male cattle had a higher sensitivity to hot temperature. The $\mathrm{pHu}$ of cows were significantly higher than continental steers, possibly due to the older slaughter age of cows, ranging between 35 months and 188 months. This agrees with the finding of Yim, Park (40) but Ahnström, Hessle (1) and Runowska, Grześ (41) did not find any pH difference due to animal age.

In the current study, cooking loss was associated with both breed and gender (Table 3). Cooking loss of meat from dairy steers were significantly $(\mathrm{P}<0.001)$ lower than that from meat from other sample groups (Figure 1). Lively, Keady (42) also reported that Holstein (dairy) beef had significantly lower cook loss than Charolais (continental) beef. Many studies have also reported lower cooking loss for steers compared to bulls (43-45).

Tenderness is one of the most important eating quality characteristics of meat (46). In this study, animal sex had a significant impact on WBSF $(\mathrm{P}<0.05)$, where beef from steers had lower WBSF compared to cows but not bulls. These results were supported by Peachey, Purchas (47) and Purchas and Aungsupakorn (48) but Moran, O'Sullivan (45) found no difference between bulls and steers for WBSF.

4.2 Confirmation of differences between sample groups for sensory profiling attributes

A total of 48 attributes were scored for the beef samples by the trained panellists. The REML analysis showed significant differences in the intensities of 35 attributes and these are shown in Table 4 . The sensory attributes that received the highest scores were grilled steak aroma, beefy flavour, tender texture on cutting, tender mouthfeel, charred external appearance, tight internal appearance and intensity of aftertaste. Similarly, a study conducted by Oltra (26) reported that charred aroma, beefy aroma, caramel appearance, char-grilled flavour, roast beef flavour and tender texture received highest score in QDA. These data reveal those sensory attributes of grilled beef that differed between these samples in aroma, flavour, mouthfeel, appearance and aftertaste.

Table 4 shows that the breed and sex interactions showed the most significant results. Figure 2 illustrates those interactions where $\mathrm{P}<0.01$. Interactions where $\mathrm{P}>0.01$ and/or which have a lower $\mathrm{P}$ value compared to the first order effects are shown in Table 4 but will not be discussed further. Both dairy steers and bulls had higher juicy external appearance compared to all other sample groups and had higher red juice external appearance compared to continental steers and dairy cows. This result was unexpected because the frozen dairy steers and bulls steaks underwent a process of partially 
thawed for further portioning, which might cause some juice loss. This indicated that the partial thawed process has limited changes on the meat. Meat from dairy steers had higher succulence mouthfeel compared to all other groups and had higher greasy external appearance compared to dairy cows, continental steers and bulls. Meat from dairy bulls had significantly higher bloody aroma (except continental cows) and bloody external appearance (except continental cows and dairy steers). Continental bulls had lower tight internal appearance, except for dairy steer. These differences highlighted the variation between sample groups.

A total of 22 attributes were significantly affected by breed, with 18 of them were significant at $\mathrm{P}<0.01$ or $\mathrm{P}<0.001$. These were especially related to appearance, aroma and flavour. For example, beef from dairy breeds received higher scores for charred aroma, grilled steak flavour, beefy flavour, greasy mouthfeel, intensity of aftertaste than continental breed. Monsón, Sañudo (49) reported that breed had significant $(\mathrm{P}<0.01)$ impacts on quantity of residual after chewing and tenderness for trained panellists. A total of 22 attributes were affected by gender, with 15 of these were significant at $\mathrm{P}<0.01$ or $\mathrm{P}<0.001$. Texture attributes were most affected, though some flavour attributes were also affected. For example, beef from steers received lower scores than bulls and cows for fibrous and spongy mouthfeel and higher scores for tender mouthfeel, crumbly mouthfeel, intensity of flavour, grilled steak flavour, and intensity of aftertaste. Other study also showed that meat from steers were tendered, less hard and firm while have higher acceptability (45).

Hanging method had significant effects on seven attributes, mostly related to texture on cutting and mouthfeel. For example, tenderstretch beef received higher scores for tender mouthfeel, spongy mouthfeel, tender and crumbly texture on cutting than straight hung beef. Surprisingly, however, hip hanging gave a higher score for roast beef aroma $(\mathrm{P}<0.001)$ and beefy flavour $(\mathrm{P}<0.05)$. While it is possible that, despite training, the panellists assessing beefy flavour were influenced by the texture, this did not apply to roast beef aroma which was assessed before the sample was transferred to the mouth. Therefore, there appears to be a real effect of hanging on flavour and aroma that justifies further investigation.

The data reported in Table 4 confirm that there were substantial and significant differences between the groups assessed by the panellists, and that this data set is therefore suitable for further evaluation of the likes and dislikes of sub-groups of the populations using cluster analysis.

4.3 Understanding differences in consumer liking using hierarchical cluster analysis 
Hierarchical cluster analysis was applied to categorise consumers according to their overall liking score. Four cluster groups were identified with $60 \%$ of similarity in the consumer overall liking score for beef striploin. The number of consumers in group 1, group 2, group 3, group 4 were 121, 85, 96 and 58, respectively, and there were no unassigned consumers. The answers to the consumer questionnaire on socioeconomic factors and attitudes to beef consumption showed that no significant $(\mathrm{P}>0.05)$ differences were observed in socioeconomic status and consumers' habit between cluster groups with the exception of frequency of consumption of minced beef $(\mathrm{P}<0.05$; appendix 1$)$. Therefore, neither age, gender, income range nor preferred "doneness" differed between cluster groups. Interestingly, a chi-square test $\left(\chi^{2}=13.82\right)$ showed that the distribution of region where the panels were conducted differed significantly $(\mathrm{P}<0.05)$ between cluster groups (Figure 3$)$, with more consumers from Republic of Ireland categorised in CG3 and higher percentage of consumers from GB categorised in CG1.

The effects of cluster group, hanging method, animal breed, animal sex and sample position on the consumer sensory scores, as determined by REML analysis, are presented in Table 5. This data shows that cluster group, hanging method, animal breed type and sex had significant $(\mathrm{P}<0.001)$ impacts on some or all of the consumer palatability traits. There were also second and third order effects (Table $5)$.

A comparison of sample groups was not the primary aim of this trial, and the two separate sources for the beef will have influenced the results. Nevertheless, the data in Table 5 show that there were some significant effects on consumer scores, and that the consumer readily differentiated between the sample groups. Only three interactions between animal effects were significant, with the highest significant effects observed for breed type and sex interaction (Table 5). Significant differences were observed for all sensory attributes for breed $\mathrm{x}$ sex interaction. Figure 4 shows that for steers all eating quality attributes were consistently better for dairy-bred beef than continental beef. Cow beef showed a similar trend, but this was only significant for juiciness, flavour liking and overall liking. For bulls the trend was for improved scores for continental beef, but this was only significant for tenderness. However, this disparity can be explained by the younger age of the continental bulls (14-15 months) compared to the dairy bulls (19 months).

Tenderness, overall liking and MQ4 scores were significantly affected by interactions between hang and sex and between sex and sample position (Table 5). The results showed that hanging method only had significant impact on bulls for tenderness, overall liking and MQ4 (Figure 5a). This result was supported by Ahnström, Hunt (35), which implies that tenderstretch can be used as a strategy to improve eating quality of bulls. Again, the lower scores for tenderness, overall liking and MQ4 score for the posterior region of the striploin was only significant $(\mathrm{P}<0.05)$ for bulls, while the anterior portion was better than the middle and posterior regions for steers only for MQ4 (Figure 5b). 
The first order effects of animal-treatments (Table 5) highlighted the differences between hanging method, breed, sex and sample position. Firstly, tenderstretch beef showed better eating quality than straight hung beef. The differences were highest for tenderness, where tenderstretch beef rated 5.8 points compared to straight hung beef (Table 5). This concurred with the QDA result, where TS beef had higher $(\mathrm{P}<0.01)$ scores for tenderness. Another study also showed that consumer scored tenderstretch higher than pelvic suspension beef (1). Previous studies have showed that shear force was highly correlated with tenderness rating (50). However, there was no difference found in shear force between both hanging methods, suggesting that consumer was more sensitive than objective measurements. Consumers preferred dairy breed beef over that from a continental breed, and the impacts were significant on juiciness $(\mathrm{P}<0.001)$, flavour liking $(\mathrm{P}<0.01)$ and overall liking $(\mathrm{P}<0.05)$. This concurred with the study conducted by Moss, Farmer (51), which showed that Holstein (dairy) beef received significantly $(\mathrm{P}<0.05)$ higher scores for tenderness, juiciness, flavour liking and overall acceptability. As expected, beef from steers had higher overall liking and MQ4 scores than bulls or cows (Table 5), which concurred with the study conducted by Venkata Reddy, Sivakumar (2). Several studies have reported that eating quality of bulls is lower (52-54). A similar conclusion was drawn by a Meat and Livestock Commission (MLC) study, which reported that suckled bulls were more tender than weaned animals (55). Therefore, the MLC Blueprint stated that young bulls are recommended to be slaughtered at less than 15 months old (56). On the other hand, position within the striploin had less impact on consumer palatability traits. As expected, the biggest impact was tenderness, where anterior sample was approximately 4 points difference with posterior sample. Likewise, another study also showed that the MSA palatability scores for striploin (Longissimus dorsi) were higher for anterior samples compared to posterior samples (57)

The four cluster groups can be categorised according to the scoring pattern and preferences that they exhibit (Table 5). Cluster group significantly $(\mathrm{P}<0.001)$ affected all palatability traits. There were several third order effects, with the highest significance observed for cluster group $\mathrm{x}$ hang $\mathrm{x}$ sex (Table 5); the remaining third order interactions are of lower significance. There are also several significant second order effects, with cluster group $\mathrm{x}$ hang and cluster group $\mathrm{x}$ sex showing widespread significance and cluster group $\mathrm{x}$ position in the muscle being significant for tenderness and MQ4. These effects are illustrated in Figures 6 and 7. Consumers in CG4 and GC1 differed mainly in overall scores, with CG4 giving average scores lower than 50 and CG1 giving average scores higher than 60 (Table 5). In addition, CG4 differentiates between AT bulls and steers and positions in the muscle, while CG1 does not (Figures 6 and 7iii). In CG1, CG3 and CG4, consumers generally rated beef from steers significantly higher $(\mathrm{P}<0.05)$ than that from bulls and cows (Figures 6 and 7ii). In contrast, consumers in CG2 liked bull beef as much as or (for TS hanging) better than steer beef, and scored cow beef the lowest (Figure 7ii). MQ4 score for bulls was greater than 50 for consumers in CG1, CG2 and CG3 (76.4\% of consumers), suggesting that meat from bulls had 
acceptable eating quality, despite the fact that bulls were excluded from MSA grading system in Australia (58). CG3 was the only cluster group that consistently perceived a significant effect of hanging method for beef from all sexes, though CG1 perceived an effect for steers only (Figures 6 and 7i). Position within the striploin muscle had significant $(\mathrm{P}<0.05)$ impacts in $\mathrm{CG} 3$ and $\mathrm{CG} 4$ only, for which anterior samples scored higher than middle samples or posterior samples, respectively (Figure 7iii). These trends highlight the variation between groups of consumers and the fact that there is no "average" consumer.

These results indicate that consumer cluster groups had different scoring patterns and liking of beef. For example, CG1 consumers could be described as "easily-pleased" as the overall average score for all palatability traits was over 60 points. CG2 was described as "bull beef likers", as this group scored TS bulls the highest (Figure 7ii). Consumers in CG3 were considered as "tender beef likers", as they preferred $(\mathrm{P}<0.05)$ TS beef than AT beef for all animal sexes (Figure 6$)$ and they also preferred $(\mathrm{P}<0.05)$ steers to the other animal sexes (Figure 7ii). CG4 consumers were considered as "fastidious" consumers, as the average score of all palatability traits were under 50, which was significantly $(\mathrm{P}<0.001)$ lower than other cluster groups (Table 5).

4.4 Understanding the relationship between instrumental measurements, QDA and consumer liking of beef using external preference mapping

Figure 8 presents an external preference map, where the principal components are based on the scores for sensory attributes from quantitative descriptive analysis. PC1 and PC2 explain 50.7\% and 27.8\% of the variation, respectively, and differentiates the beef striploin on flavour, appearance, mouthfeel and texture attributes. PC3 (not shown), explained a further $8.5 \%$ and differentiated primarily on aroma and flavour. The internal preference map based on consumer scores was also analysed and showed the same relationships. This is not presented as no extra information was derived.

External preference mapping showed the key drivers of liking and which beef was favoured by consumers. The average consumer scores and overall liking cluster groups are correlated on the same axes. Figure 8 shows that the average consumer overall liking score was closest to T3b and T4b, which were dairy steers. Indeed, it is notable that the trained panel differentiated the beef samples very clearly with breed separated by the continuous line (continental breed distributed on the left and dairy breed distributed on the right) and quality on the cattle's sex separated by the two dashed lines (cows located in the top region, bulls in the middle region and steers in the bottom region).

Consumer scores for overall liking, aroma liking, tenderness, juiciness and flavour liking are highly related to profiling attributes from QDA, including tender mouth-feel, tender texture on cutting, intensity of flavour, intensity of aftertaste, succulence mouth-feel, sweet flavour, beefy flavour and 
roast beef flavour. Negative attributes, such as spongy mouth-feel and fibrous texture on cutting, were located at the opposite regions to the consumer overall liking score on the preference maps. The results obtained from this study appear to be in agreement with those reported by Oltra, Farmer (25) using lamb meat, where consumer preferences were closely associated with meat aftertaste, roast lamb flavour, tenderness, sweet flavour, while rubbery texture appeared in the opposite direction. A study conducted by Oltra, Farmer (23) also showed that consumers' overall liking of beef was highly associated with tender texture, sweet flavour and juiciness. Furthermore, in Figure 8, WBSF was situated opposite to tenderness and overall liking while cooking loss was negatively associated with juiciness or succulence MOU. Even though the endpoint temperatures of samples for instrumental analysis and sensory analyses were different, it appears that the relative tenderness between samples is discerned by both methods. This concurred with the results reported by Oltra, Farmer (23), where WBSF was situated opposite to overall liking and related with chewy, rubbery and stringy. The fact that tenderness was only partially explained by WBSF supports the findings of Caine, Aalhus (59) who stated that WBSF only accounted for $37 \%$ and $36 \%$ of initial and overall tenderness of trained panel sensory characteristics. Perry, Thompson (60) concluded that shear force had a quadratic relationship with tenderness score by trained panel.

The cluster groups, CG1, CG3 and CG4 cluster groups were located close together, clustered around the average consumer palatability traits. Consumers in these cluster groups were highly associated with steers. However, the scoring patterns of consumers varied as shown in Table 5. The consumers in CG1, CG3 and CG4 were described as "easy-pleased", "tender beef liker" and "fastidious" consumers respectively. In contrast, CG2 was separated from other cluster groups and located in a different region that associated with bulls. This agreed with the result showed in Figure 6 and Figure 7ii. Therefore, CG2 consumers were described as "bull beef liker".

These result show that cluster analysis provides suggestions about consumer liking of beef associated with sensory attributes. Such categorisation could be very useful for classifying consumers' liking and understanding consumers' attitudes towards beef attributes, particularly for the implementation of the marketing strategies and the development of meat products.

\subsection{Conclusion}

External preference mapping showed that consumers' overall liking of beef was associated with intensity of flavour, tender mouthfeel, succulence mouthfeel and roast beef flavour. In contrast, mouthfeel attributes such as spongy and form balls had negative influences on consumer perceptions. Animal sex and breed were separated across the external preference map with a distinct pattern and 
demonstrated relationships with different sensory attributes. Four cluster groups were derived, with distinctive differences in mean sensory score and liking of beef. CG1, CG2, CG3, CG4 represented "easily-pleased", "bull beef liker", "tender beef liker" and "fastidious" consumers respectively. Most consumers liked TS steers the most, except for consumers in CG2.

This study showed that the technique of cluster analysis can categorise consumers into groups according to their scoring pattern or liking of beef. The technique of external preference mapping outlined the relationship between consumers' overall liking, instrumental measurements, specific sensory attributes and cluster groups.

6.0 Acknowledgement

The study was funded through the Agriculture and Food's Food Institutional Research Measure (FIRM: 13 SN 401) in Republic of Ireland Department as part of the National Development Plan 2007-2013.

\subsection{References}

1. Ahnström ML, Hessle A, Johansson L, Hunt MC, Lundström K. Influence of slaughter age and carcass suspension on meat quality in Angus heifers. Animal. 2012;6(9):1554-62.

2. Venkata Reddy B, Sivakumar AS, Jeong DW, Woo YB, Park SJ, Lee SY, et al. Beef quality traits of heifer in comparison with steer, bull and cow at various feeding environments. Animal Science. 2015;86(1):1-16.

3. Oliver MA, Nute GR, Font i Furnols M, San Julián R, Campo MM, Sañudo C, et al. Eating quality of beef, from different production systems, assessed by German, Spanish and British consumers. Meat Science. 2006;74(3):435-42.

4. Labbe D, Rytz A, Hugi A. Training is a critical step to obtain reliable product profiles in a real food industry context. Food Quality and Preference. 2004;15(4):341-8.

5. Wheeler TL, Papadopoulos LS, Miller MF. Research guidelines for cookery, sensory evaluation, and instrumental tenderness measurements of meat. American Meat Science Association; 2015.

6. Farmer L, Devlin DJ, Gault N, A G, Gordon A, Moss B, et al. Prediction of eating quality using the Meat Standards Australia system for Northern Ireland beef and consumers. In Proceedings of the 55th International Congress on Meat Science and Technology. 2009:PE 7.34.

7. Polkinghorne RJ, editor Targeting the consumer demand for beef in Australia, Japan, Korea, Ireland, and the United States. 60th Reciprocal Meat Conference American Meat Science Association; 2007.

8. Campo MM, Nute GR, Hughes SI, Enser M, Wood JD, Richardson RI. Flavour perception of oxidation in beef. Meat Science. 2006;72(2):303-11.

9. Behrends JM, Goodson KJ, Koohmaraie M, Shackelford SD, Wheeler TL, Morgan WW, et al. Beef customer satisfaction: factors affecting consumer evaluations of calcium chloride-injected top sirloin steaks when given instructions for preparation. Journal Of Animal Science. 2005;83(12):286975. 
10. Chong FS, Farmer LJ, Hagan TDJ, Moloney AP, Kerry JP, O'Sullivan MG, editors. Consumer acceptability of beef in regions of the British Isles? 64th International Congress of Meat Science and Technology; 2018; Melbourne, Australia.

11. Chong FS, Farmer L, Hagan TDJ, Speers JS, Sanderson DW, Devlin DJ, et al. Regional, socioeconomic and behavioural- impacts on consumer acceptability of beef in northern ireland, republic of ireland and great britain. Meat Science. 2019.

12. Banović M, Chrysochou P, Grunert KG, Rosa PJ, Gamito P. The effect of fat content on visual attention and choice of red meat and differences across gender. Food Quality and Preference. 2016;52:42-51.

13. Dubost A, Micol D, Lethias C, Listrat A. New insight of some extracellular matrix molecules in beef muscles. Relationships with sensory qualities. Animal : an international journal of animal bioscience. 2016;10(5):821-8.

14. Stone H, Bleibaum R, Thomas H. Sensory Evaluation Practices. 4th Edition ed2012.

15. Endrizzi I, Gasperi F, Rødbotten M, Næs T. Interpretation, validation and segmentation of preference mapping models. Food Quality and Preference. 2014;32:198-209.

16. van Kleef E, van Trijp HCM, Luning P. Internal versus external preference analysis: An exploratory study on end-user evaluation. Food Quality and Preference. 2006;17(5):387-99.

17. Tyron RC. Cluster Analysis: Correlation Profile and Orthometric (Factor) Analysis for the Isolation of Unities in Mind and Personality. Brothers E, Arbor A, editors1939.

18. Schilling MW, Coggins PC. Utilization of Agglomerative Hierarchical Clustering in the Analysis of Hedonic Scaled Consumer Acceptability Data. Journal of Sensory Studies. 2007;22(4):477-91.

19. Kaye-Blake W, O'Connell A, Lamb C. Potential market segments for genetically modified food: Results from cluster analysis. Agribusiness. 2007;23(4):567-82.

20. Tleis M, Callieris R, Roma R. Segmenting the organic food market in Lebanon: an application of k-means cluster analysis. British Food Journal. 2017;119(7):1423-41.

21. Marino R, Della Malva A, Seccia A, Caroprese M, Sevi A, Albenzio M. Consumers' expectations and acceptability for low saturated fat 'salami': healthiness or taste? Journal of the Science of Food and Agriculture. 2017;97(11):3515-21.

22. Drake MA, McIngvale SC, Gerard PD, Cadwallader KR, Civille GV. Development of a Descriptive Language for Cheddar Cheese. Journal of Food Science. 2001;66(9):1422-7.

23. Oltra OR, Farmer L, Moss B, Gordon AW, Birnie J. External preference mapping of beef: Relationship of fatty acids and flavour precursors with consumer's preferences. Advances in Animal Biosciences. 2010;1(1):130.

24. Schmidt TB, Schilling MW, Behrends JM, Battula V, Jackson V, Sekhon RK, et al. Use of cluster analysis and preference mapping to evaluate consumer acceptability of choice and select bovine $\mathrm{M}$. Longissimus Lumborum steaks cooked to various end-point temperatures. Meat Science.

2010;84:46-53.

25. Oltra OR, Farmer L, Gordon AW, Moss BW, Birnie J, Devlin DJ, et al. Identification of sensory attributes, instrumental and chemical measurements important for consumer acceptability of grilled lamb Longissimus lumborum. Meat Science. 2015;100:97-109.

26. Oltra OR. Strategies to optimize the eating quality of beef and lamb meat: Queen's University Belfast; 2010.

27. Pirsich W, Weinrich R. The Impact of Sustainability Aspects in the Meat Sector: A Cluster Analysis Based on Consumer Attitudes and Store Format Choice. Journal of International Food \& Agribusiness Marketing. 2018:1-25.

28. Lively FO, Moss BW, Keady TWJ, Patterson DC, Gordon AW, editors. The effect of genotype and carcass hanging method on meat quality. 51st International Congress of Meat Science and Technology; 2005; Baltimore, Maryland USA.

29. Holman BWB, Fowler SM, Hopkins DL. Are shear force methods adequately reported? Meat Science. 2016;119:1-6. 
30. Watson R, Gee A, Polkinghorne R, Porter M. Accessory Publication: MSA sensory testing protocols. Australian Journal of Experimental Agriculture2008. p. 1360-7.

31. Hwang IH, Polkinghorne R, Lee JM, Thompson JM. Demographic and design effects on beef sensory scores given by Korean and Australian consumers. Australian Journal of Experimental Agriculture. 2008;48(11):1387-95.

32. MacFie HJH, Thomson DMH. Measurement of food preferences. London: Blackie Academic; 1994.

33. Zhuang H, Savage EM. Comparison of cook loss, shear force, and sensory descriptive profiles of boneless skinless white meat cooked from a frozen or thawed state1. Poultry Science. 2013;92(11):3003-9.

34. Hutchison CL, Mulley RC, Wiklund E, Flesch JS. Consumer evaluation of venison sensory quality: effects of sex, body condition score and carcase suspension method. Meat Science. 2010;86(2):311-6.

35. Ahnström ML, Hunt MC, Lundström K. Effects of pelvic suspension of beef carcasses on quality and physical traits of five muscles from four gender-age groups. Meat Science. 2012;90:52835.

36. England EM, Matarneh SK, Mitacek RM, Abraham A, Ramanathan R, Wicks JC, et al. Presence of oxygen and mitochondria in skeletal muscle early postmortem. Meat Science. 2018;139:97-106.

37. Katz LS. Sexual behavior of domesticated ruminants. Hormones and Behavior. 2007;52(1):56-63.

38. Field RA, Nelms GE, Schoonover CO. Effects of Age, Marbling and Sex on Palatability of Beef. Journal of Animal Science. 1966;25(2):360-6.

39. Węglarz A. Meat quality defined based on $\mathrm{pH}$ and colour depending on cattle category and slaughter season. colour and $\mathrm{pH}$ as determinants of meat quality dependent on cattle category and slaughter season. Czech Journal of Animal Science. 2010;55(No. 12):548-56.

40. Yim D-G, Park S-W, Chung K-Y. Physicochemical traits of Holstein loin and top round veal from two slaughter age groups. Journal of animal science and technology. 2015;57(1):24-.

41. Runowska GC, Grześ B, Pospiech E, Komisarek J, Okulicz M, Stanisławski D, et al. Meat quality of Limousin young bulls slaughtered at 6, 9 and 12 months of age. Emirates Journal of Food and Agriculture. 2017;29(10):792-8.

42. Lively FO, Keady TWJ, Moss BW, Patterson DC, Kilpatrick DJ, editors. The effect of genotype, carcass weight and fat classification, and pelvic hanging technique on meat quality. Processing of the British Society of Animal Science; 2005 April 2005.

43. Cafferky J, Hamill RM, Allen P, O'Doherty JV, Cromie A, Sweeney T. Effect of Breed and Gender on Meat Quality of M. Iongissimus thoracis et lumborum Muscle from Crossbred Beef Bulls and Steers. Foods (Basel, Switzerland). 2019;8(5):173.

44. Ozawa S, Mitsuhashi T, Mitsumoto M, Matsumoto S, Itoh N, Itagaki K, et al. The characteristics of muscle fiber types of longissimus thoracis muscle and their influences on the quantity and quality of meat from Japanese Black steers. Meat Science. 2000;54(1):65-70.

45. Moran L, O'Sullivan MG, Kerry JP, Picard B, McGee M, O'Riordan EG, et al. Effect of a grazing period prior to finishing on a high concentrate diet on meat quality from bulls and steers. Meat Science. 2017;125:76-83.

46. Guillemin N, Bonnet M, Jurie C, Picard B. Functional analysis of beef tenderness. Journal of Proteomics. 2011;75(2):352-65.

47. Peachey BM, Purchas RW, Duizer LM. Relationships between sensory and objective measures of meat tenderness of beef $\mathrm{m}$. longissimus thoracis from bulls and steers. Meat Science. 2002;60(3):211-8.

48. Purchas RW, Aungsupakorn R. Further investigations into the relationship between ultimate $\mathrm{pH}$ and tenderness for beef samples from bulls and steers. Meat Sci. 1993;34(2):163-78.

49. Monsón F, Sañudo C, Sierra I. Influence of breed and ageing time on the sensory meat quality and consumer acceptability in intensively reared beef. Meat Science. 2005;71:471-9. 
50. Rhee MS, Wheeler TL, Shackelford SD, Koohmaraie M. Variation in palatability and biochemical traits within and among eleven beef muscles. Journal of Animal Science.

2004;82(2):534-50.

51. Moss B, Farmer L, Gault N, Tolland E. Beef from the Dairy herd. Agri-Food \& Biosciences Institute: Agri-Food \& Biosciences Institute, Northern Ireland,; 2009.

52. L. Griffin C, M. Stiffler D, C. Smith G, W. Savell J. Consumer Acceptance of Steaks and Roasts from Charolais Crossbred Bulls and Steers2006. 165-8 p.

53. Klastrup S. Comparison of meat quality in steers and young bulls at different liveweights and feed levels. . Kreaturer-Kodkvalitet. 1984;Danish Meat Research Institute.

54. Rodbotten R, Berg J, Hildrum KI, Wold JP. Meat from steers has superior quality compared with bulls. In: Duffy G, editor. Advancing Beef Safety and Quality through Research and Innovation: An international conference organised by ProSafeBeef; Teagasc, Food Research Centre, Ashtown, Dublin2010.

55. Fisher A, Nute G, Matthews K, Wood J, editors. Differences in tenderness between bulls and steers: effects in different muscles. International Congress of Meat Science and Technology; 2001; Krakow, Poland.

56. Matthews KR. Review of published literature and unpublished research on factors influencing beef quality. Agriculture and Horticulture Development Board; 2011.

57. Thompson JM. Managing meat tenderness. Meat Science. 2002;62:295-308.

58. Bonny SPF, O'Reilly RA, Pethick DW, Gardner GE, Hocquette J-F, Pannier L. Update of Meat Standards Australia and the cuts based grading scheme for beef and sheepmeat. Journal of Integrative Agriculture. 2018;17(7):1641-54.

59. Caine WR, Aalhus JL, Best DR, Dugan MER, Jeremiah LE. Relationship of texture profile analysis and Warner-Bratzler shear force with sensory characteristics of beef rib steaks. Meat Science. 2003;64(4):333-9.

60. Perry D, Thompson JM, Hwang IH, Butchers A, Egan AF. Relationship between objective measurements and taste panel assessment of beef quality. Australian Journal of Experimental Agriculture. 2001;41(7):981-9. 
Table 1

Sample group information.

\begin{tabular}{ccccc}
\hline Group & Animal Sex & Hanging method & Breed & Number of striploins \\
\hline T1a & Bulls & AT & Continental & 6 \\
T1b & Bulls & AT & Dairy & 6 \\
T2a & Bulls & TS & Continental & 6 \\
T2b & Bulls & TS & Dairy & 6 \\
T3a & Steers & AT & Continental & 6 \\
T3b & Steers & AT & Dairy & 6 \\
T4a & Steers & TS & Continental & 6 \\
T4b & Steers & TS & Dairy & 6 \\
T5a & Cows & AT & Continental & 6 \\
T5b & Cows & AT & Dairy & 6 \\
T6a & Cows & TS & Continental & 6 \\
T6b & Cows & TS & Dairy & 6 \\
\hline
\end{tabular}

AT: Straight Hung, TS: Tenderstretch

Table 2

Abbreviation and definition for sensory attributes.

\begin{tabular}{llll}
\hline Group & Attributes & Abbreviations & Definition \\
\hline Aroma (AR) & Roast Beef & RstBf AR & Aroma of outside of roasted joint \\
& Grilled steak & GrilStk AR & Aroma reminiscent of meat browned on grill \\
Beefy & Beefy AR & Aroma of inner core of roast beef \\
Charred & Char AR & Burnt charcoal aroma \\
& Fatty & Fatty AR & Aroma of fatty animal or lard \\
Bloody & Bloody AR & Aroma of reminiscent of metallic, blood \\
& Mealy & Mealy AR & Aroma related to cooked animal feed \\
& Herby & Herby AR & Herbs, green aroma \\
& Acrid & Acrid AR & Pungent, acrid aroma \\
& Farmyard & Farmyard AR & Animal, farmyard odour \\
& Spice & Spice AR & Sausage spice aroma \\
\cline { 2 - 3 } & & &
\end{tabular}




\begin{tabular}{|c|c|c|c|}
\hline \multirow[t]{12}{*}{ Flavour (FL) } & Intensity of Flavour & Intensity FL & Strength of flavour \\
\hline & Grilled Steak & GrilStk FL & Flavour reminiscent of meat browned on grill \\
\hline & Roast Beef & RstBf FL & Flavour of outer $1 \mathrm{~cm}$ of roasted joint \\
\hline & Beefy & Beefy FL & Flavour of inner core of roast beef \\
\hline & Char Grilled & CharGrill FL & Burnt charcoal-like flavour \\
\hline & Metallic/ Bloody & Metallic FL & Flavour of reminiscent of blood \\
\hline & Saltiness & Salty FL & Salt flavour in the mouth \\
\hline & Sour/ Acidic & Sour FL & Sour milk, lactic flavour \\
\hline & Bitterness & Bitter FL & Bitter flavour in the mouth \\
\hline & Sweetness & Sweet FL & Sweet beef flavour \\
\hline & Earthy & Earthy FL & Root vegetable flavour \\
\hline & Rancid & Rancid FL & Rancid oil, distinct rancid flavour \\
\hline \multirow{3}{*}{$\begin{array}{l}\text { Texture on } \\
\text { cutting (TC) }\end{array}$} & Tenderness & Tender TC & Easily cut, soft texture \\
\hline & Crumbly/ Dry & Crumbly TC & Sample separates, crumbs form during cutting \\
\hline & Fibrous/ Stringy & Fibrous TC & Long strands in the meat on cutting \\
\hline \multirow{7}{*}{$\begin{array}{l}\text { Mouth-feel } \\
\text { (MOU) }\end{array}$} & Tenderness & Tender MOU & Soft and easy to chew before swallowing \\
\hline & Spongy/Rubbery & Spongy MOU & Rubbery, keeps its shape, chewy \\
\hline & Succulence & Succule MOU & Juicy mouthfeel \\
\hline & Sticky/ Clingy & Sticky MOU & Sticks to teeth and roof of the mouth \\
\hline & Forms Balls & Balls MOU & Forms balls when chewing \\
\hline & Crumbly & Crumbly MOU & Sample separates after chewing \\
\hline & Greasy & Greasy MOU & Oil coating on the roof of the mouth \\
\hline \multirow{8}{*}{$\begin{array}{l}\text { External } \\
\text { appearance } \\
\text { (EXAP) }\end{array}$} & Pale colour & Pale EXAP & Pale colour of meat \\
\hline & $\begin{array}{l}\text { Chestnut colour/ } \\
\text { Brownness }\end{array}$ & Chestnut EXAP & Brown colour of cooked meat \\
\hline & Juicy & Juicy EXAP & Liquid juice around the meat \\
\hline & Charred & Char EXAP & Black or well-cooked on outer surface \\
\hline & Bloody & Bloody EXAP & Pink and undercooked bloody outer surface \\
\hline & Redness of juice & RedJui EXAP & Red juice on surface and plate \\
\hline & Brownness of juice & $\begin{array}{l}\text { BrownJui } \\
\text { EXAP }\end{array}$ & Brown juices on surface and plate \\
\hline & Greasy/ Oily/ Fatty & Greasy EXAP & Overall oily bright surface \\
\hline \multirow{2}{*}{$\begin{array}{l}\text { Internal } \\
\text { appearance } \\
\text { (INAP) }\end{array}$} & Tight & Tight INAP & Closely packed between fibres, close grain \\
\hline & Lean & Lean INAP & No obvious internal fat \\
\hline
\end{tabular}




\begin{tabular}{|c|c|c|c|}
\hline \multirow[t]{5}{*}{ Aftertaste (AF) } & $\begin{array}{l}\text { Intensity of } \\
\text { Aftertaste }\end{array}$ & Intensity AF & Strength of aftertaste \\
\hline & Roast Beef & RstBf AF & Aftertaste of outside of roasted joint \\
\hline & Acidic & Acidic AF & Sour aftertaste in the mouth \\
\hline & Bitterness & Bitter AF & Bitter aftertaste in the mouth \\
\hline & Saltiness & Salty AF & Salty aftertaste in the mouth \\
\hline
\end{tabular}

Table 3

Predicted means and average standard deviation of the $\mathrm{pH}$, WBSF and cook loss from 12 sample groups.

\begin{tabular}{llll}
\hline & $\mathrm{pHu}$ & WBSF (kgf) & Cook loss (\%) \\
\hline Hang (H) & & & \\
AT & 5.57 & 4.67 & 26.89 \\
TS & 5.52 & 4.47 & 26.74 \\
SED & 0.030 & 0.151 & 0.452 \\
$\boldsymbol{P}$ & 0.120 & 0.207 & 0.751
\end{tabular}

\section{Breed (B)}

Continental $5.56 \quad 4.59$

$\begin{array}{llll}\text { Dairy } & 5.53 & 4.55 & 25.88 \\ \text { SED } & 0.030 & 0.151 & 0.452 \\ \boldsymbol{P} & 0.407 & 0.816 & <0.001\end{array}$

\section{$\operatorname{Sex}(\mathbf{S})$}

$\begin{array}{llll}\text { Steers } & 5.47^{\mathrm{a}} & 4.29^{\mathrm{a}} & 25.52^{\mathrm{a}} \\ \text { Bulls } & 5.59^{\mathrm{b}} & 4.66^{\mathrm{ab}} & 27.70^{\mathrm{b}} \\ \text { Cows } & 5.58^{\mathrm{b}} & 4.77^{\mathrm{b}} & 27.23^{\mathrm{b}} \\ \text { SED } & 0.037 & 0.185 & 0.554 \\ \boldsymbol{P} & 0.003 & 0.034 & <0.001\end{array}$

\section{Interaction}

$\begin{array}{llll}\text { H x B } & 0.163 & 0.403 & 0.735 \\ \text { H x S } & 0.266 & 0.792 & 0.736 \\ \text { B x S } & 0.028 & 0.083 & <0.001 \\ \text { H x B x S } & 0.377 & 0.948 & 0.604\end{array}$


a,b,c: Numbers in the same column which do not share a common superscript are significantly different $(\mathrm{P}<0.05)$. $\mathrm{SED}=$ average standard error, $P=$ probability, $\mathrm{pHu}=$ ultimate $\mathrm{pH}, \mathrm{WBSF}=$ Warner Bratzler Shear Force. 
Predicted means and average standard deviation of the intensity scores for the sensory attributes.

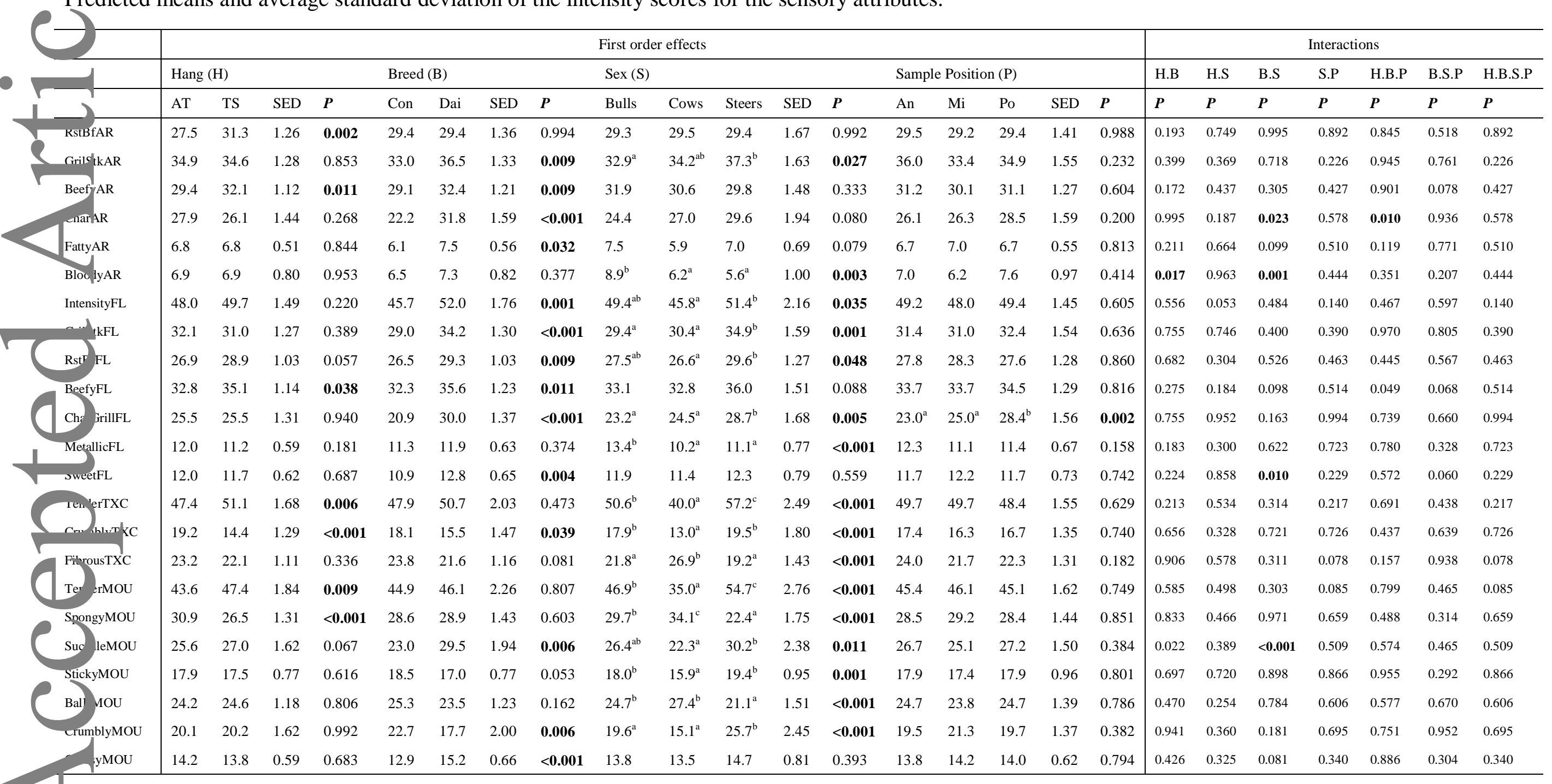

This article is protected by copyright. All rights reserved. 
Table 5

Effects of cluster group, hanging method, breed, animal sex and sample position on consumer sensory scores.

\begin{tabular}{|c|c|c|c|c|c|c|}
\hline & $\mathrm{AL}$ & $\mathrm{TE}$ & $\mathrm{JU}$ & $\mathrm{FL}$ & OL & MQ4 \\
\hline \multicolumn{7}{|l|}{ Cluster group (CG) } \\
\hline CG1 (121 consumers) & $66.5^{\mathrm{c}}$ & $61.8^{\mathrm{c}}$ & $62.6^{\mathrm{c}}$ & $66.7^{\mathrm{c}}$ & $66.8^{\mathrm{c}}$ & $64.8^{\mathrm{c}}$ \\
\hline CG2 (85 consumers) & $57.9^{\mathrm{b}}$ & $52.3^{\mathrm{b}}$ & $52.4^{\mathrm{b}}$ & $56.3^{\mathrm{b}}$ & $55.4^{\mathrm{b}}$ & $54.4^{\mathrm{b}}$ \\
\hline CG3 (96 consumers) & $56.8^{\mathrm{b}}$ & $52.3^{\mathrm{b}}$ & $51.8^{\mathrm{b}}$ & $55.0^{\mathrm{b}}$ & $54.9^{\mathrm{b}}$ & $53.8^{\mathrm{b}}$ \\
\hline CG4 (58 consumers) & $46.7^{\mathrm{a}}$ & $41.2^{\mathrm{a}}$ & $39.4^{\mathrm{a}}$ & $40.8^{\mathrm{a}}$ & $39.7^{\mathrm{a}}$ & $40.5^{\mathrm{a}}$ \\
\hline SED & 1.88 & 1.66 & 1.82 & 1.54 & 1.39 & 1.35 \\
\hline $\boldsymbol{P}$ & $<0.001$ & $<0.001$ & $<0.001$ & $<0.001$ & $<0.001$ & $<0.001$ \\
\hline \multicolumn{7}{|l|}{ Hang (H) } \\
\hline AT & 55.8 & 49.4 & 50.2 & 52.7 & 52.0 & 51.2 \\
\hline TS & 58.1 & 54.4 & 52.9 & 56.7 & 56.4 & 55.6 \\
\hline SED & 0.97 & 1.72 & 1.33 & 1.19 & 1.29 & 1.30 \\
\hline$P$ & 0.017 & $<0.001$ & 0.017 & $<0.001$ & $<0.001$ & $<0.001$ \\
\hline \multicolumn{7}{|l|}{ Breed (B) } \\
\hline Continental & 55.7 & 50.9 & 48.2 & 52.6 & 52.2 & 51.5 \\
\hline Dairy & 58.2 & 52.9 & 54.9 & 56.8 & 56.2 & 55.3 \\
\hline SED & 1.16 & 2.25 & 1.66 & 1.45 & 1.62 & 1.66 \\
\hline$P$ & 0.052 & 0.782 & $<0.001$ & 0.009 & 0.044 & 0.079 \\
\hline \multicolumn{7}{|l|}{$\operatorname{Sex}(S)$} \\
\hline Bulls & $57.9^{\mathrm{b}}$ & $55.1^{\mathrm{b}}$ & $52.5^{\mathrm{b}}$ & $55.7^{\mathrm{b}}$ & $55.9^{\mathrm{b}}$ & $55.2^{\mathrm{b}}$ \\
\hline Cows & $53.3^{\mathrm{a}}$ & $38.3^{\mathrm{a}}$ & $44.6^{\mathrm{a}}$ & $47.3^{\mathrm{a}}$ & $45.1^{\mathrm{a}}$ & $43.7^{\mathrm{a}}$ \\
\hline Steers & $59.6^{\mathrm{b}}$ & $62.3^{c}$ & $57.6^{c}$ & $61.1^{c}$ & $61.6^{\mathrm{c}}$ & $61.2^{\mathrm{c}}$ \\
\hline SED & 1.41 & 2.74 & 2.03 & 1.77 & 1.98 & 2.03 \\
\hline$P$ & $<0.001$ & $<0.001$ & $<0.001$ & $<0.001$ & $<0.001$ & $<0.001$ \\
\hline \multicolumn{7}{|l|}{ Position (P) } \\
\hline Anterior & 58.1 & $54.6^{\mathrm{b}}$ & $52.5^{\mathrm{b}}$ & 56.2 & $55.9^{\mathrm{b}}$ & $55.3^{\mathrm{b}}$ \\
\hline Middle & 56.5 & $50.9^{\mathrm{a}}$ & $52.5^{\mathrm{b}}$ & 54.4 & $53.7^{\mathrm{a}}$ & $52.9^{\mathrm{a}}$ \\
\hline Posterior & 56.3 & $50.2^{\mathrm{a}}$ & $49.6^{\mathrm{a}}$ & 53.5 & $52.9^{\mathrm{a}}$ & $52.0^{\mathrm{a}}$ \\
\hline SED & 1.00 & 1.19 & 1.17 & 1.09 & 1.05 & 0.99 \\
\hline$P$ & 0.446 & $<0.001$ & 0.043 & 0.092 & 0.033 & 0.008 \\
\hline \multicolumn{7}{|c|}{ Interaction (without CG) } \\
\hline H.B & 0.998 & 0.484 & 0.697 & 0.208 & 0.143 & 0.266 \\
\hline H.S & 0.889 & 0.026 & 0.053 & 0.079 & 0.027 & 0.017 \\
\hline B.S & 0.041 & 0.004 & $<0.001$ & 0.001 & $<0.001$ & $<0.001$ \\
\hline H.P & 0.904 & 0.031 & 0.540 & 0.789 & 0.394 & 0.244 \\
\hline B.P & 0.747 & 0.190 & 0.819 & 0.969 & 0.915 & 0.716 \\
\hline S.P & 0.358 & 0.002 & 0.146 & 0.079 & 0.005 & 0.008 \\
\hline H.B.S & 0.545 & 0.320 & 0.162 & 0.425 & 0.148 & 0.222 \\
\hline H.B.P & 0.930 & 0.668 & 0.690 & 0.956 & 0.983 & 0.881 \\
\hline H.S.P & 0.656 & 0.066 & 0.337 & 0.215 & 0.112 & 0.090 \\
\hline B.S.P & 0.325 & 0.698 & 0.787 & 0.792 & 0.945 & 0.928 \\
\hline Interaction (with CG) & & & & & & \\
\hline
\end{tabular}




\begin{tabular}{lllllll}
\hline CG.H & 0.001 & $<0.001$ & $<0.001$ & $<0.001$ & $<0.001$ & $<0.001$ \\
CG.B & 0.231 & 0.500 & 0.923 & 0.671 & 0.650 & 0.758 \\
CG.S & $<0.001$ & $<0.001$ & $<0.001$ & $<0.001$ & $<0.001$ & $<0.001$ \\
CG.P & 0.180 & 0.031 & 0.054 & 0.072 & 0.090 & 0.029 \\
CG.H.B & 0.668 & 0.053 & 0.375 & 0.298 & 0.220 & 0.133 \\
CG.H.S & 0.112 & $<0.001$ & 0.012 & 0.004 & $<0.001$ & $<0.001$ \\
CG.B.S & 0.117 & 0.260 & 0.084 & 0.181 & 0.107 & 0.088 \\
CG.H.P & 0.033 & 0.348 & 0.046 & 0.277 & 0.030 & 0.161 \\
CG.B.P & 0.984 & 0.017 & 0.175 & 0.774 & 0.171 & 0.112 \\
CG.S.P & 0.583 & 0.241 & 0.035 & 0.008 & 0.054 & 0.038 \\
\hline
\end{tabular}

a,b,c,..,f: Numbers in the same column which do not share a common superscript are significantly different $(\mathrm{P}<0.05) .{ }^{\$} \boldsymbol{A} \boldsymbol{L}$ : aroma liking, $\boldsymbol{T E}$ : tenderness, $\boldsymbol{J U}$ : juiciness, $\boldsymbol{F} \boldsymbol{L}$ : flavour liking, $\boldsymbol{O} \boldsymbol{L}$ : overall liking. Group information may be found in Table 1 . $\mathrm{SED}=$ standard error, $\boldsymbol{P}=$ probability.

(i) $\mathrm{pHu}, \mathrm{P}<0.05$

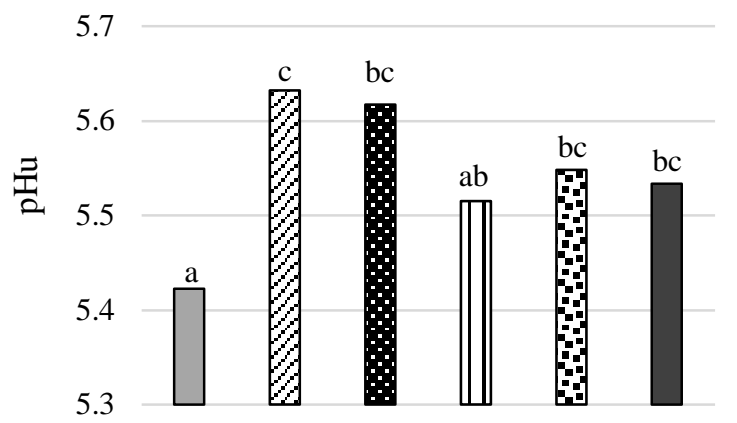

(ii) Cook loss, $\mathrm{P}<0.001$

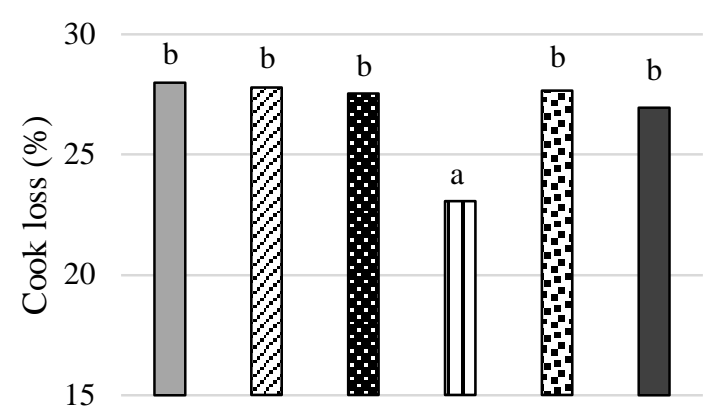

$\square$ Continental Steers $₫$ Continental Bulls $\mathbf{x}$ Continental Cows $₫$ Dairy Steers $₫$ Dairy Bulls $\square$ Dairy Cows

Figure 1 Effect of breed $\mathrm{x}$ sex interaction on $\mathrm{pHu}$ and cook loss. 


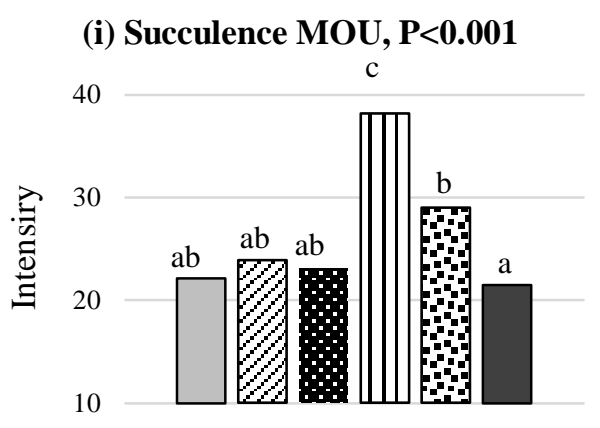

(iii) Bloody AR, P<0.01

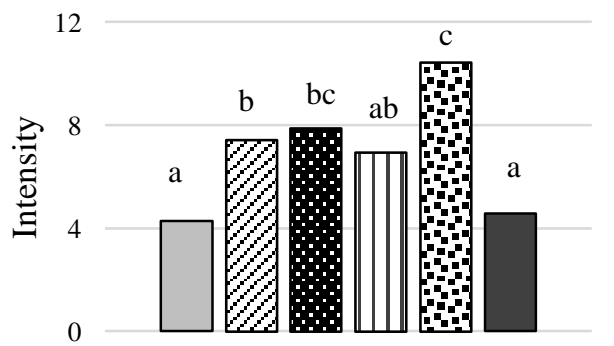

(v) Greasy EXAP, P<0.01

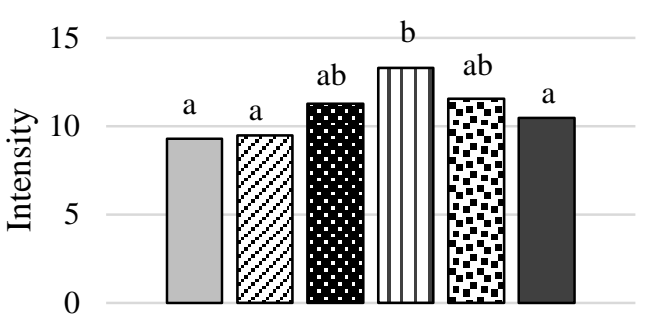

(vii) TightINAP, $\mathbf{P}<0.01$

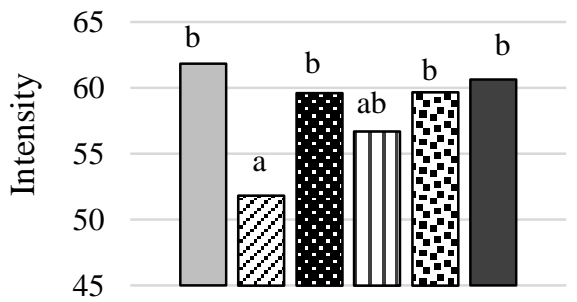

(ii) Juicy EXAP, P<0.001

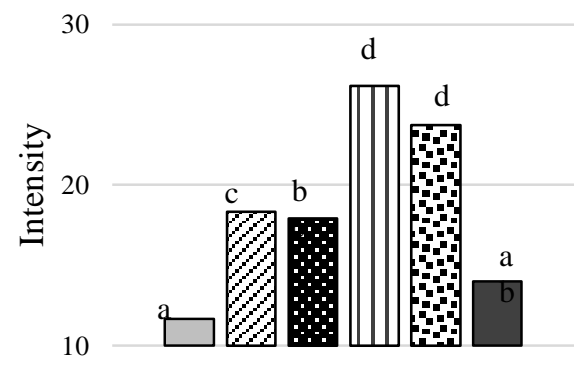

(iv) BloodyEXAP, P<0.01

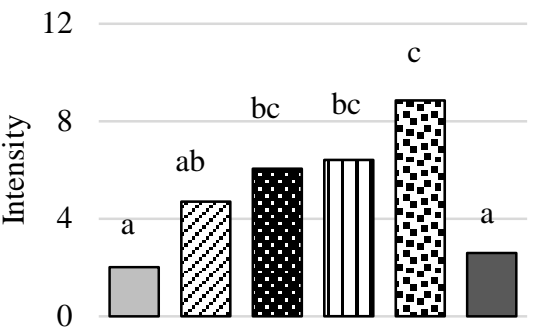

(vi) RedJuiEXAP, P<0.01

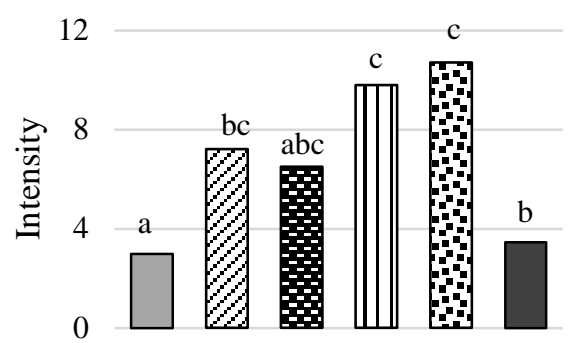

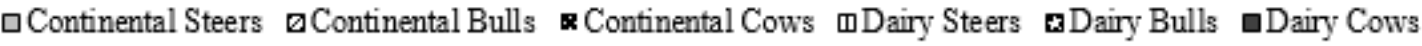

Figure 2 Effect of breed $x$ sex interaction on (i) succulence mouthfeel, (ii) juicy external appearance and (iii)bloody aroma, (iv) bloody external appearance, (v) greasy external appearance, (vi) red juice external appearance and (vii) tight internal appearance. 


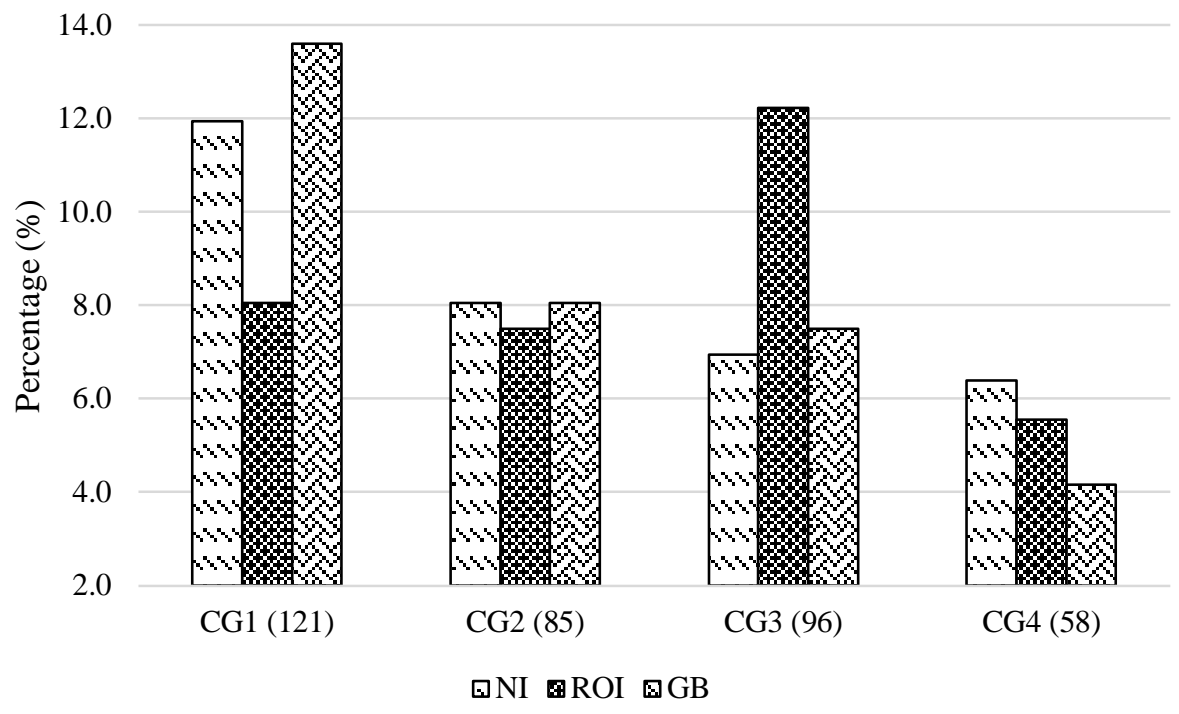

Figure 3 Regional distribution of members of cluster groups (CG). $\chi^{2}=13.82(\mathrm{P}<0.05)$. The data is presented in percentage of 360 consumers.

(i) $\mathrm{AL}$

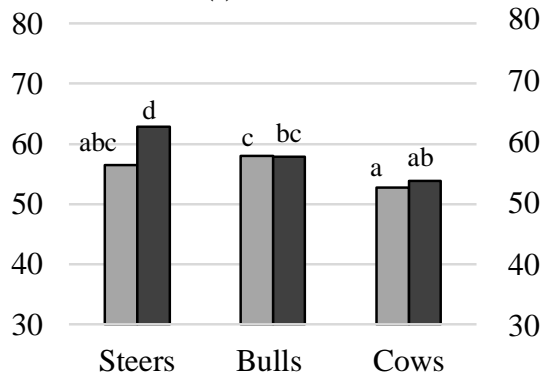

(iv) FL

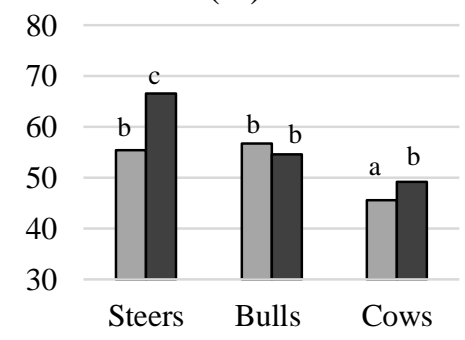

(ii) TE

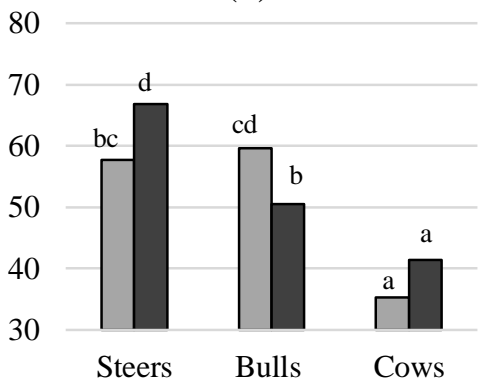

(v) $\mathrm{OL}$

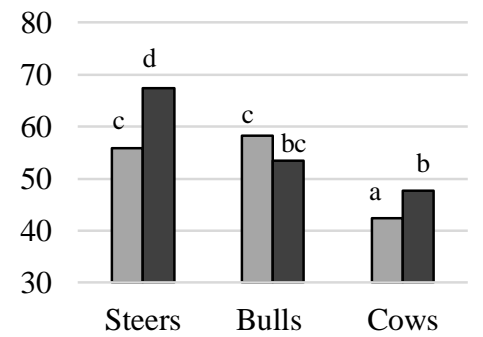

(iii) $\mathrm{JU}$

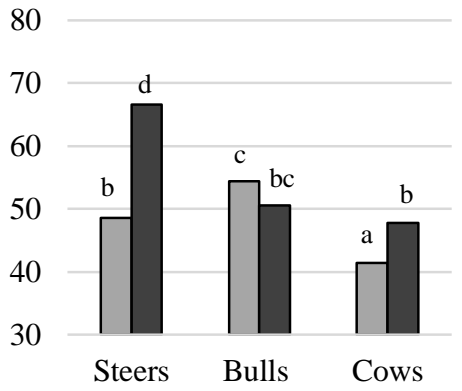

(vi) MQ4

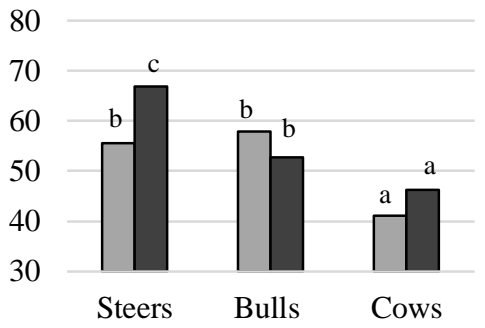

$\square$ Continental $\square$ Dairy

Figure 4 Effect of breed and sex interaction on (i) aroma liking (AL), (ii) tenderness (TE), (iii) juiciness (JU), (iv) flavour liking (FL), (v) overall liking (OL) and (vi) MQ4 scores of consumer panel. For significance, see Table 5. 
$\mathrm{a}(\mathrm{i}): \mathrm{TE}$

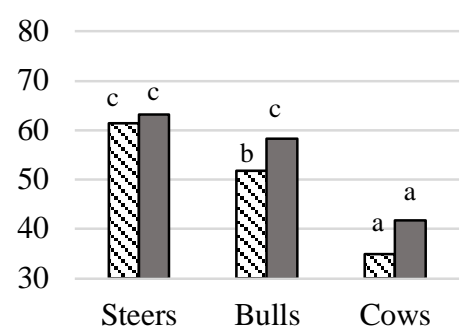

$b(i): T E$

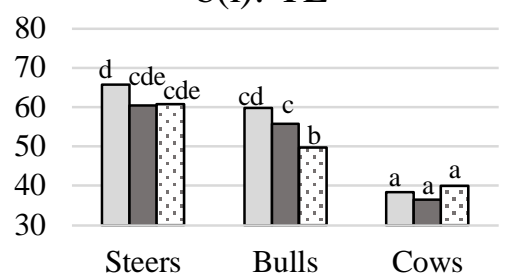

a(ii): OL

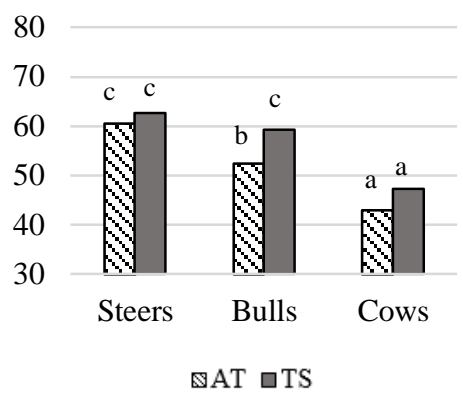

b(ii): OL

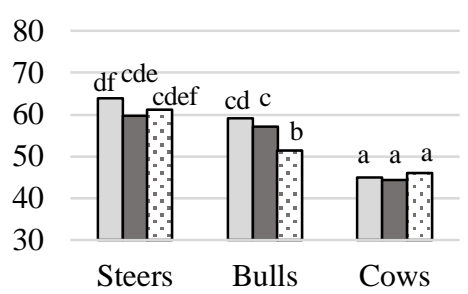

a(iii): MQ4

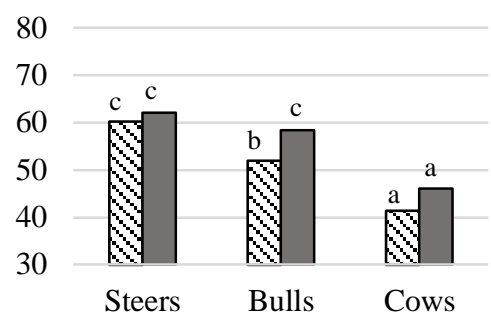

b(iii) MQ4

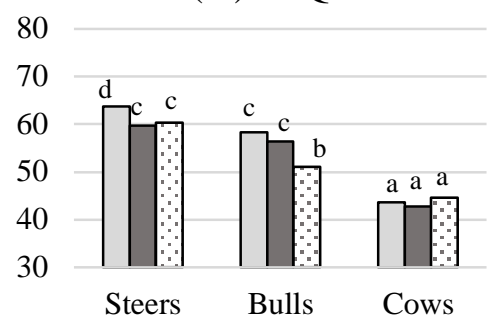

$\square$ Anterior $\square$ Middle $\bullet$ Posterior

Figure 5 Effects of (a) hang and sex interaction and (b) sex and sample position interaction on (i) tenderness (TE), (ii) overall liking (OL) and (iii) MQ4 score. For significance, see Table 5.

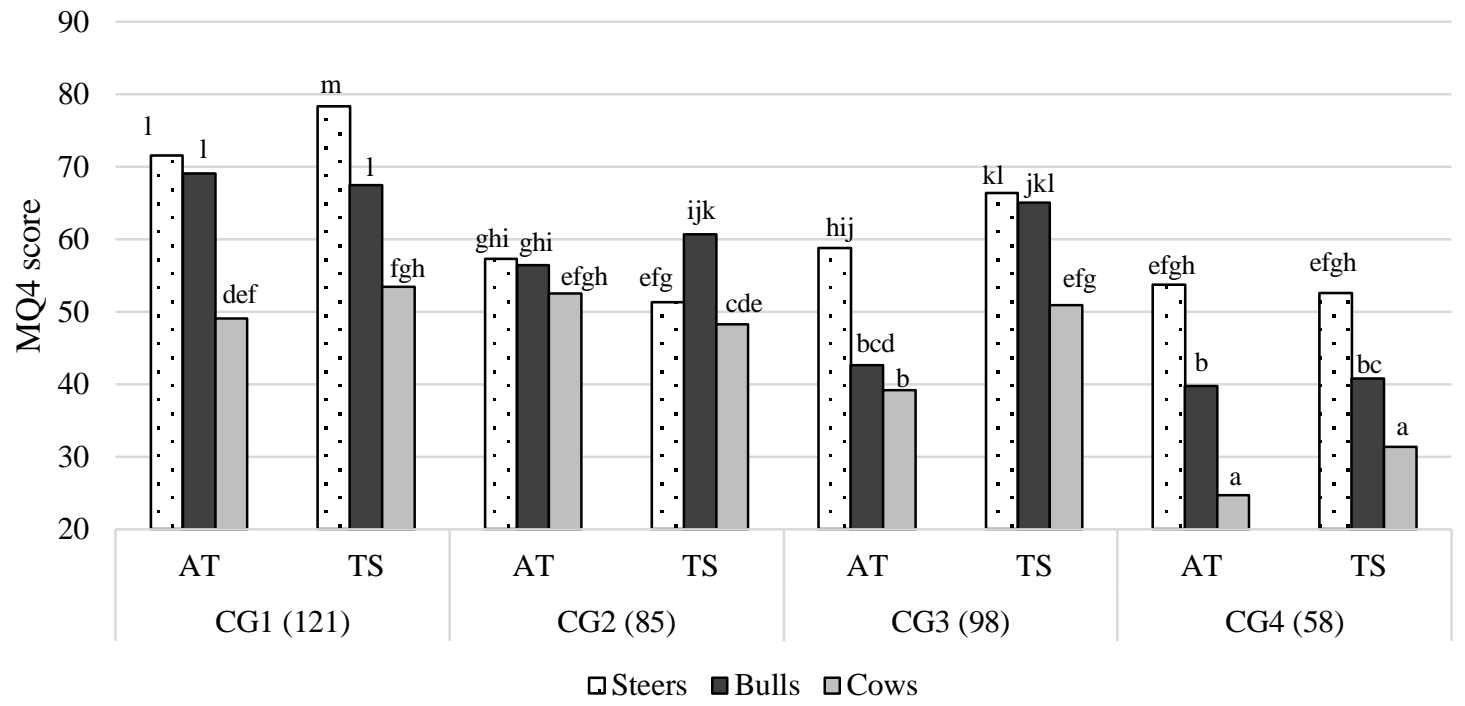

Figure 6 Effect of cluster group $\mathrm{x}$ hanging method $\mathrm{x}$ animal sex on MQ4 score. Number of consumer in each cluster group is included in bracket. For significance, see Table 5. 
(i) Hanging method, $\mathrm{P}<0.001$

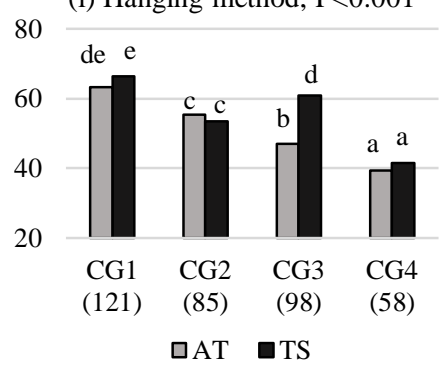

(ii) $\mathrm{Sex}, \mathrm{P}<0.001$

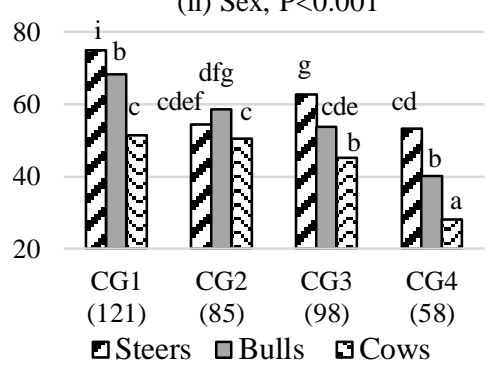

(iii) Sample position, $\mathrm{P}<0.05$

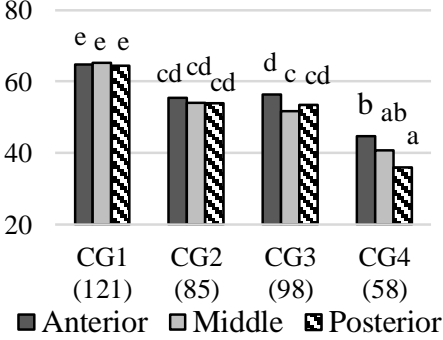

Figure 7 Effect of interactions of cluster group with (i) hanging method, (ii) sex and (iii) sample position interactions on MQ4 score. Number of consumer in each cluster group is included in bracket.

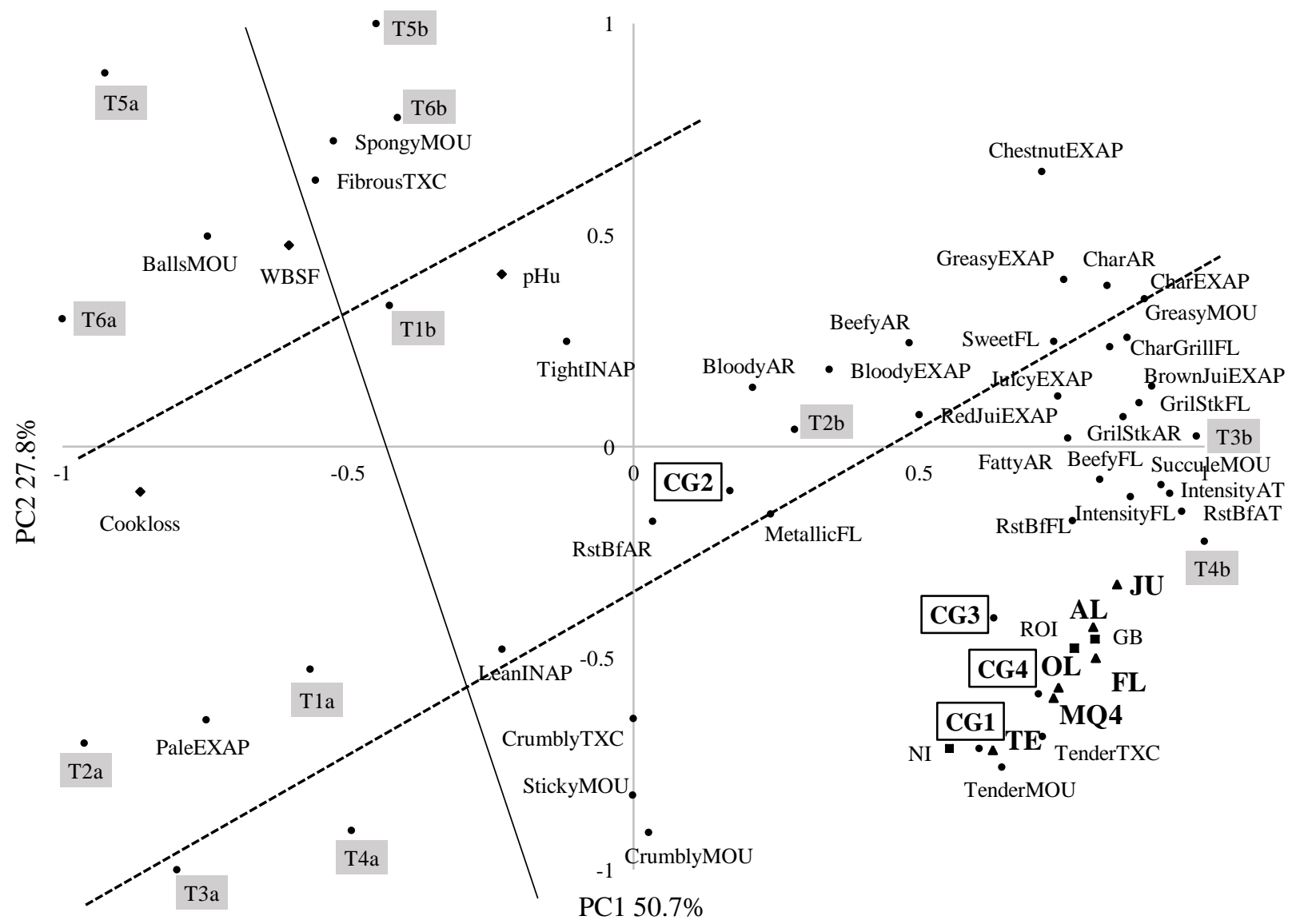

Figure 8 External preference map. Consumer sensory scores (triangle), sensory profiling panel attributes (circle) and instrumental analysis (diamond), region (square), cluster groups (square background). Groups (grey background) are listed on the map. Abbreviations: $A R=A r o m a, F L=$ Flavour, EXAP= External appearance, INAP= Internal appearance, $\mathrm{TC}=$ Texture on cutting, MOU= Mouth-feel, $\mathrm{AF}=$ Aftertaste, $\mathrm{CG}=$ cluster group, $\mathrm{NI}=$ Northern Ireland, $\mathrm{ROI}=$ Republic of Ireland, $\mathrm{GB}=$ Great Britain. Consumer scores were highlighted in bold, $\mathrm{AL}=$ aroma liking, $\mathrm{TE}=$ tenderness, $\mathrm{FL}=$ flavour liking, $\mathrm{JU}=$ juiciness, $\mathrm{OL}=$ overall liking and MQ4 scores. 